\title{
Circulating cell-free DNA concentration and DNase I activity of peripheral blood plasma change in case of pregnancy with intrauterine growth restriction compared to normal pregnancy
}

\author{
ELIZAVETA ERSHOVA $^{1,2}$, VASILINA SERGEEVA ${ }^{1}$, MARIA KLIMENKO ${ }^{3}$, \\ KRISTINA AVETISOVA ${ }^{3}$, PETER KLIMENKO ${ }^{3}$, EDMUND KOSTYUK ${ }^{4}$, NATALIA VEIKO ${ }^{1,2}$, \\ ROMAN VEIKO $^{1}$, VERA IZEVSKAYA ${ }^{1}$, SERGEY KUTSEV ${ }^{1}$ and SVETLANA KOSTYUK ${ }^{1,2}$ \\ ${ }^{1}$ Federal State Budgetary Institution 'Research Centre For Medical Genetics', Moscow 115478; \\ ${ }^{2}$ Federal State Budgetary Institution 'V.A. Negovsky Research Institute of General Reanimatology', \\ Moscow 107031; ${ }^{3}$ Pediatric Faculty, Pirogov Russian National Research Medical University, \\ Moscow 117997; ${ }^{4}$ Center of Family Planning and Reproduction, Moscow 117209, Russia
}

Received April 7, 2017; Accepted June 30, 2017

DOI: 10.3892/br.2017.968

\begin{abstract}
The level of apoptosis is increased during pregnancy. Dying cells emit DNA that remains in blood circulation and is known as cell-free DNA (cfDNA). The concentration of cfDNA can reflect the level of cell death. The present article is the result of studying cfDNA concentration and DNase I activity in the blood plasma of 40 non-pregnant women (control), 40 healthy pregnant women (over 37 weeks) and 40 pregnant women with a diagnosis of intrauterine growth restriction (IUGR). In order to explain the obtained results, a program modeling the change of cfDNA concentration under the influence of different internal and external factors was written. It was reported that, despite the fact that the level of cell death is increased, cfDNA concentration in blood can be decreased due to activation of cfDNA elimination system. A significant increase of DNase I activity has been reported in cases of IUGR. Increase in DNase I activity over a certain threshold indicates presence of pathological processes in the organism. CfDNA circulating in blood cannot be a reliable marker of increased cell death during pregnancy. Thus, assessment of the level of cell death during pregnancy should be done by simultaneous analysis of cfDNA level and DNase I activity.
\end{abstract}

Correspondence to: Mrs. Vasilina Sergeeva, Federal State Budgetary Institution 'Research Centre For Medical Genetics', 1 Moskvorechie, Moscow 115478, Russia

E-mail: tracytheplane@gmail.com

${ }^{*}$ Contributed equally

Key words: extracellular DNA, circulating DNA, cell-free DNA, pregnancy, DNase I, intrauterine growth restriction

\section{Introduction}

It is well known that blood contains circulating cell-free DNA (cfDNA) (1-9). There are several hypotheses concerning the origin of cfDNA, including the cell death hypothesis and the hypothesis that living cells actively secrete DNA as signaling molecules. CfDNA is a potential marker for pathological processes and is of importance for diagnostic purposes (1-9).

cfDNA in a fetus was first reported to be present in maternal blood in 1997, when Lo et al (10) demonstrated that maternal plasma contains Y-chromosomal sequence of the male fetus. This discovery led to development of new non-invasive prenatal diagnosis techniques. cfDNA analysis detects genetic abnormalities of the fetus (11). In 2014, whole fetal genome was sequenced from cfDNA in maternal plasma (12).

Apart from genetic abnormalities of the fetus, cfDNA analysis allows monitoring pregnancy-related complications such as preeclampsia and preterm birth (13-15). In this case instead of a search for gene mutations, concentration of general cfDNA or fetal cfDNA in maternal plasma is analyzed. Fetal cfDNA comprises up to $10 \%$ of all cfDNA in maternal plasma and is believed to be released by necrotic and apoptotic cells of placenta (16).

Intrauterine growth restriction (IUGR) is a complex disorder of pregnancy with varying etiology. It is characterized by the failure of the fetus to achieve its normal growth potential and is associated with perinatal morbidity and mortality. Long-term consequences include a higher risk of cardiovascular diseases $(13,17)$. One of the primary causes of IUGR is placental dysfunction that often leads to increased death of placental cells. Death of cells of placenta results in increased concentration of cell-free fetal DNA in maternal plasma, contributing to the overall cfDNA concentration.

Data concerning changes in concentrations of fetal and maternal cfDNA in cases of IUGR are scarce and controversial. In the first research (16), authors did not find any discrepancy between cfDNA concentrations in cases of normal pregnancies and the ones with IUGR. Later studies indicated 
that cfDNA concentrations are increased in cases of pregnancies with IUGR (18-21). It is of importance that in these studies the authors did not take into account the processes of elimination of cfDNA from plasma. Increase in cfDNA concentration as a consequence of cell death leads to activation of cfDNA eliminating system, thus, effectively decreasing the concentration of cfDNA. The authors have observed the effect of significant decrease of cfDNA concentration in cases of chronic processes (that are accompanied by increased cell death) such as cardiovascular diseases (22). The same effect occurs in people chronically working with radiation. This can be due to the activity of DNase I - one of the components of cfDNA elimination system (23).

In the current study, the authors assessed cfDNA concentration changes simultaneously with DNase I activity in plasma of non-pregnant women, women with normal pregnancies and pregnancies complicated by IUGR. The results have demonstrated that cfDNA concentration in maternal blood plasma is not a reliable marker of IUGR in third trimester of pregnancy. Simultaneous analysis of cfDNA concentration and DNase I activity can, however, provide valuable information about IUGR development.

\section{Materials and methods}

Sample of participants. The investigation was carried out in accordance with the latest version of the Declaration of Helsinki and approved by the Regional Ethics Committee of Research Centre For Medical Genetics (Moscow, Russia; approval no. 5). All participants signed an informed written consent to participate after the nature of the procedures had been fully explained.

Analyzed sample consisted of three groups of women of relatively the same age (22-40 years old) living in Moscow in the same social environment. The groups are as follows: Group I, non-pregnant, healthy women $(n=40)$, consisting of students and employees of the medical facility (volunteers); group II, women with normal pregnancy $>37$ weeks $(n=40)$, that later bore healthy children without signs of hypoxia or hypotrophy; group III, women with pregnancy complicated with IUGR > 30 weeks, that later on bore children with IUGR signs $(\mathrm{n}=40)$. A total $5 \mathrm{ml}$ of blood was collected under strict aseptic conditions from a peripheral vein of the subject using a syringe flushed with heparin $(0.1 \mathrm{ml} / 5 \mathrm{ml}$ blood $)$.

Prenatal screening. Fetal development during pregnancy was screened with help of ultrasound anthropometry. Biparietal diameter of the head, chest circumference, abdominal circumference and femur length were measured. When these measurements were behind the population mean, by 2 weeks IUGR of stage 1 was diagnosed; 2 to 4 weeks stage 2 IUGR; more than 4 weeks stage 3 of IUGR. The final IUGR status was diagnosed after birth based on body mass. Normative parameters were between 75 and 25 percentile curves, first stage of IUGR 25 curve 10; second stage of IUGR 10 curve 3; third stage below curve 3 . In addition to this, the weight-for-height index was used: Healthy, $>60$; IUGR stage 1, 55-60; stage 2, 50-55; stage $3,<50$.

The functional state of the fetuses during pregnancy and labor was assessed with help of functional diagnostic methods such as cardiotocography and dopplerometry of uterine, umbilical and fetal blood vessels.

Plasma cfDNA concentration (cfDNA index). Cells were removed from the blood by centrifugation at $460 \mathrm{x} \mathrm{g}$, followed by mixing of $3 \mathrm{ml}$ plasma with $0.3 \mathrm{ml}$ of the solution containing $1 \%$ sodium lauroyl sarcosinate, 0.02 M EDTA, and $75 \mu \mathrm{g} / \mathrm{ml}$ RNase A (Sigma-Aldrich; Merck KGaA, Darmstadt, Germany), incubation for $45 \mathrm{~min}$, then the treatment with proteinase K $(200 \mu \mathrm{g} / \mathrm{ml}$; Promega Corporation, Madison, WI, USA) for $24 \mathrm{~h}$ at $37^{\circ} \mathrm{C}$. Following two cycles of the purification with saturated phenolic solution, DNA fragments were precipitated by adding two volumes of ethanol in the presence of $2 \mathrm{M}$ ammonium acetate. The precipitate was then washed with $75 \%$ ethanol twice, then dried and dissolved in water. The concentration of DNA (cfDNA index) was determined by measuring fluorescence intensity on 'LS 55' (PerkinElmer, Inc., Waltham, MA, USA) spectrometer after DNA staining with the PicoGreen (Invitrogen; Thermo Fisher Scientific, Inc., Waltham, MA, USA). The relative standard error of the index cfDNA was $10 \pm 4 \%$.

DNase I activity in plasma. Levels of DNase I activity in plasma samples were measured by the single radial enzyme diffusion method, as described previously (24). The assay method can determine pg to fg quantities of DNase I in $1 \mathrm{ml}$ serum samples within $30 \mathrm{~min}$. One unit of enzyme assayed corresponds to $1 \mathrm{ng}$ purified human DNase I. Relative standard error of the index DNase I was $15 \pm 5 \%$.

Statistical analysis and modeling. All reported results were reproduced at least three times as independent biological replicates. The significance of the observed differences was analyzed using the non-parametric Mann-Whitney U-tests. $\mathrm{P}<0.05$ was considered to indicate a statistically significant difference. Data were analyzed with StatPlus2007 Professional software (http://www.analystsoft.com/).

ApoModel2 software was written by Roman Veiko (Research Centre For Medical Genetics, Moscow, Russia) in Object Pascal language with the help of an integrated media Turbo Delphi 2006 development. Software designed to simulate changes for the cfDNA under the influence of external and internal factors (e.g., exposure to radiation or pathology associated with the induction of apoptosis in cells in the body). The input data of the model were: The level of damages in the cell; the level of damages in the cell after reaching which it enters apoptosis; an increase in the number of lesions after exposure; the amount of DNA in the cell (in pg); the number of cells; the initial percentage of cells with damage; the number of damaging actions; DNA percentage remaining in the cell after degradation.

Functional input parameters were: The time function of reducing the amount of extracellular DNA as a result of elimination; function for apoptotic cells release of DNA into the extracellular environment. Functions can be set using a special formula designer and generator values. The output parameters of the model were the magazine states of the system, which were created during the simulation. The magazine reflected the number of dead cells, the number of surviving cells and the amount of extracellular and intracellular DNA. 

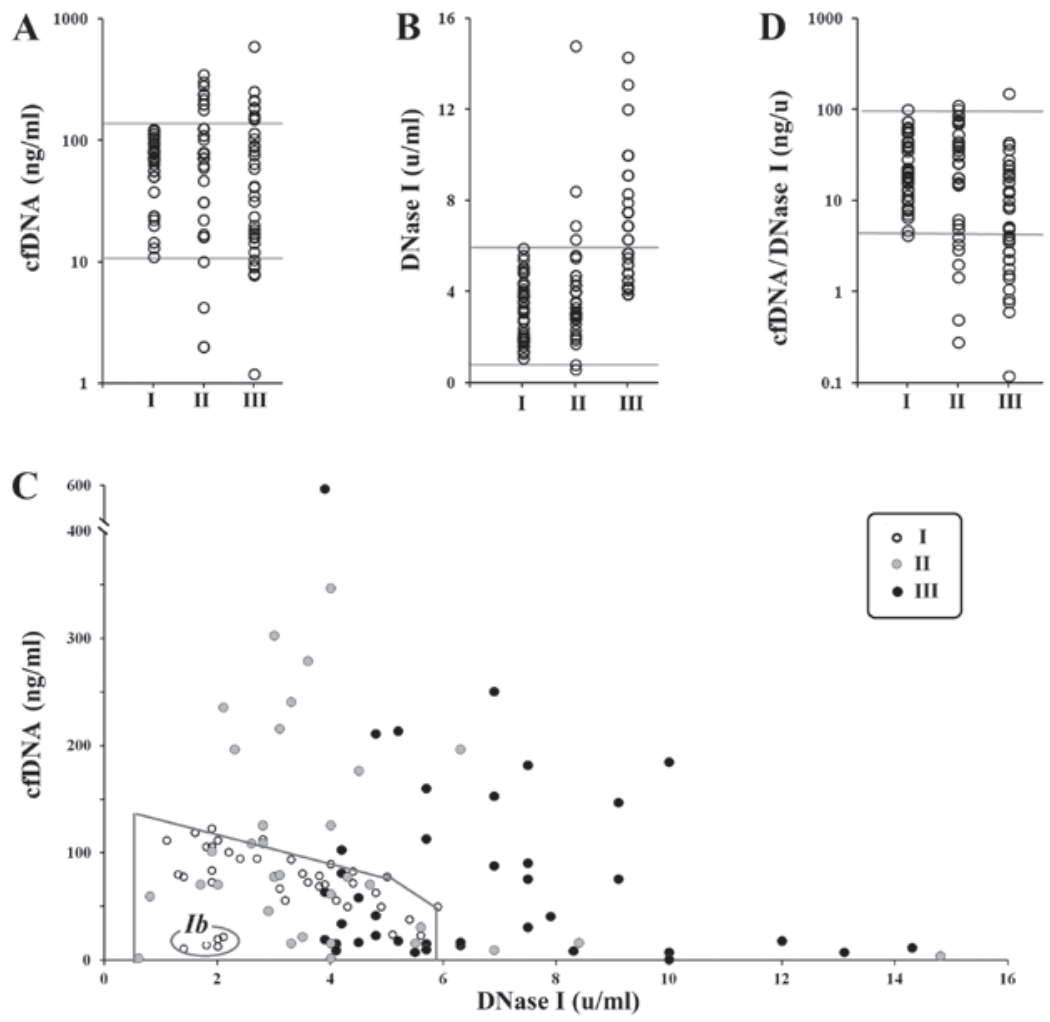

Figure 1. (A) CfDNA concentration, (B) DNase I activity and (D) index cfDNA/DNase I for three cohorts. I, non-pregnant women; II, healthy pregnant women; III, pregnant women with IUGR. (C) Dependence of cfDNA concentration in blood plasma of women on DNase I activity. Marked area is the values for non-pregnant women (group I). Group II, gray circles; group III, black circles. cfDNA, cell-free DNA.

\section{Results}

cfDNA concentration ( $c f D N A$ index). CfDNA was isolated from the samples of blood plasma of 120 women. DNA concentrations were determined using the DNA binding dye PicoGreen. Fig. 1A presents cfDNA concentration in the blood plasma (Table I for descriptive statistics). Group I $(n=40)$, non-pregnant women; group II $(\mathrm{n}=40)$, women with normal pregnancy (gestational age 30-41 weeks); and group III $(n=40)$, women with pregnancies complicated by IUGR (gestational age 30-41 weeks).

There was no statistical difference between the three groups regarding cfDNA index $(\mathrm{P}>0.05)$. However, in nine women of groups II and III (22\%), the authors observed elevated concentration of cfDNA as compared to the controls (Fig. 1A). In the third group, cfDNA concentrations were somewhat lower than in group II. If the single highest outlier is removed from group III $(596 \mathrm{ng} / \mathrm{ml})$, there is a persistent decrease in cfDNA concentration in group III compared to group II $(\mathrm{P}<0.05$; NII $=40, \mathrm{NIII}=39)$.

Thus, the expected increase of cfDNA concentration in the blood of pregnant women compared to non-pregnant was not observed. Moreover, in troubled pregnancies, where a significant increase in cfDNA concentration was expected, the authors discovered a decrease in the concentration of cfDNA compared to healthy pregnancy. One of the primary reasons of cfDNA concentration decrease can be activation of the cfDNA elimination system of blood. One of the factors here is the activity of the blood plasma enzyme responsible for the cfDNA fragmentation, DNase I.
DNase I activity (DNase I index). DNase I activity in blood plasma of 120 women was determined by the standard radial diffusion method (24). The DNase I indices for the groups are provided in Fig. 1A and in Table I. No significant difference was detected between the groups I and II by this index ( $\mathrm{P}>0.05)$.

The third group, however, differs from group I $(\mathrm{P}<0.0000001)$ and group II $(\mathrm{P}<0.00001)$. Thus, plasma of pregnant women with IUGR contains highly active DNase I compared to blood plasma of healthy pregnant or non-pregnant women. A total of 19 out of $40(47.5 \%)$ women from the group III had very high activity of DNase I in their blood, that were not present in the non-pregnant women sample. In group II, only 4 (10\%) patients had increased DNase I activity compared to non-pregnant women.

Dependence of cfDNA concentration on DNase I activity. Dependence of cfDNA concentration on DNase I activity is shown of Fig. 1C. Marked area is the field of data for non-pregnant women (group I). Non-pregnant women can be divided into two groups: Ia and Ib. Group Ia consists of 35 women $(87.5 \%)$ and is characterized by linear dependence of cfDNA concentration on DNase I activity. Ib consists of 5 women who had low cfDNA concentration $(11-22 \mathrm{ng} / \mathrm{ml})$ and low DNase I activity $(1.4-2.1 \mathrm{U} / \mathrm{ml})$.

Marked area on the Fig. 1C corresponding to non-pregnant women included 25 (subgroup IIa) and 16 (IIIa) women from groups II and III. It is of importance, that the activity of DNase I for the subgroup IIIa in this area is higher than the activity of DNase I for groups I and IIa $(\mathrm{P}>0.05)$. 
Table I. Statistics for the parameters defined in the study.

\begin{tabular}{lccc}
\hline Parameter & $\begin{array}{c}\text { Cohort I } \\
(\mathrm{n}=40)\end{array}$ & $\begin{array}{c}\text { Cohort II } \\
(\mathrm{n}=40)\end{array}$ & $\begin{array}{c}\text { Cohort III } \\
(\mathrm{n}=40)\end{array}$ \\
\hline ffDNA, ng/ml & & & \\
Mean & $72 \pm 32$ & $101 \pm 88$ & $83 \pm 109$ \\
Var & 0.45 & 0.87 & 1.32 \\
Median & 76 & 78 & 41 \\
Interval & $11-123$ & $2-347$ & $1-596$ \\
DNase I, U/ml & & & \\
Mean & $3.1 \pm 1.4$ & $3.9 \pm 2.3$ & $6.7 \pm 2.6$ \\
Var & 0.45 & 0.60 & 0.39 \\
Median & 2.9 & 3.4 & 5.7 \\
Interval & $1.1-5.9$ & $0.6-14.8$ & $3.9-14.3$ \\
cfDNA/DNase I, & & & \\
ng/ $\mu$ l & & & $15 \pm 25$ \\
Mean & $30 \pm 24$ & $34 \pm 30$ & 1.7 \\
Var & 0.79 & 0.91 & 8.3 \\
Median & 21 & 26 & $0.1-153$ \\
Interval & $4-102$ & $0.3-112$ & \\
\hline
\end{tabular}

cfDNA, cell-free DNA.

All the other patients from groups II (subgroup IIb) and III (subgroup IIIb) are beyond the marked area that contains all the non-pregnant women. For these women, the authors identified a linear dependence between cfDNA concentration and DNase I activity. Linear regression equations (cfDNA=A-b*DNase I) reflecting the dependence in all three groups are shown below.

Ia) cfDNA $=123-13 *$ DNase I $(n=35), \mathrm{k}=-0.8, \mathrm{P}<<0,0001$; IIb) cfDNA=275-21*DNase I $(\mathrm{n}=15), \mathrm{k}=-0.7, \mathrm{P}<0.01$; IIIb) cfDNA=354-30*DNase $\mathrm{I}(\mathrm{n}=24), \mathrm{k}=-0.62, \mathrm{P}<0.002$.

Coefficient $\mathrm{A}$ in the equation is the hypothetic average cfDNA concentration in absence of DNase I (DNase I=0). This level reflects the amount of dying cells under the same conditions. Thus, the levels of cell death are: Group I (non-pregnant) < group II (healthy pregnancy) < group III (IUGR).

Coefficient $b$ reflects the rate of cfDNA elimination when the DNase I is activated. This coefficient is increasing in a row: group I (non-pregnant) < group II (healthy pregnancy) < group III (IUGR).

Increase in DNase I activity affects cfDNA concentration in blood plasma of group III patients much stronger than patients of other groups. The authors introduced an index that reflects the amount of cfDNA for one unit of DNase I activity: cfDNA/ DNase I (Fig. 1D and Table I for descriptive statistics). The difference between cfDNA/DNase I indices for samples I and II is not statistically significant $(\mathrm{P}>0.05)$. Sample III differs from sample I $(\mathrm{P}<0.001)$ and sample II $(\mathrm{P}<0.001)$.

Dependence of IUGR features on cfDNA, DNase I and cfDNA/DNase I. IUGR can be characterized by objective parameters such as mass and height of the fetus and mass-to-height index. The authors analyzed the dependence of these characteristics and duration of gestation on cfDNA concentration, DNase I activity and the cfDNA/DNase I index with help of linear regression method (Table II). cfDNA concentration and cfDNA/DNase I index correlate negatively with all characteristics of the fetus. The higher the cfDNA concentration and the cfDNA/DNase I index are, the lower are the mass and height of the fetus and the shorter is duration of gestation. DNase I activity does not correlate with these factors (Table II).

Modeling of changes of cfDNA concentration. Apomodel 2 software allowed the authors to set the level of injury and subsequent apoptosis, to analyze the amount of DNA entering into the extracellular medium from the dead cells and to take into account the processes that lead to the elimination of cfDNA. It is assumed that a damaging agent is acting on the cells. If the damage is above a given level, the cell is destroyed and DNA enters into the extracellular medium. cfDNA is constantly removed from the medium. Fig. 2 provides the results of modeling. The dependence of the amount of cfDNA in the medium from the time of observation. The time interval of observation was 3 months. For the function of the DNA release from the dead cells arbitrarily accepted expression: $y=1 / x$, where $x=$ time after a regular exposure.

\section{Discussion}

It is a matter of common knowledge that various endogenous and exogenous factors can affect the cell death rate in the organism. Dying cells release DNA into the bloodstream contributing to the pool of circulating cfDNA (1-9). cfDNA is an active biological agent. For example, cfDNA can alter hemodynamic properties of the blood $(2,25)$. It can induce oxidative stress, stimulate proinflammatory cytokine synthesis and induce sterile inflammation (26). The organism defense against cfDNA is the cfDNA elimination system of the blood. cfDNA elimination system knockout in animals causes lupus-like autoimmune disease $(27,28)$. Healthy non-pregnant women have a negative correlation between cfDNA concentration in blood and DNase I activity (Fig. 1C). Apparently, DNase I activity is the main factor regulating elimination of the cfDNA from the bloodstream in this case. As been indicated previously, $\sim 10 \%$ of people have low cfDNA concentration and low DNase I activity (23). These people have low level of cell apoptosis in their body. People from this group are more resistant to external negative factors such as chronic ionizing radiation. Possible reasons for low cell death may include increased activity of antioxidant and reparation systems. The group Ib (Fig. 1C) consists of women who have low level of cell death.

Modeling of the basic processes that lead to a change in the amount of circulating DNA shows that, despite a 10-fold increase in the level of cell damage, the authors observe a significant reduction in amount of cfDNA due to activation of the cfDNA elimination (Fig. 2). The modeling results correspond well with the previously obtained experimental data. It has been reported that chronic human exposure to ionizing radiation leads to a significant reduction in the cfDNA concentration while the level of cell damage remains above the control level (23). In addition, it was demonstrated 
Table II. Linear regression analysis of fetus features and pregnancy duration dependence on cfDNA concentration, DNase I activity and cfDNA/DNase I index for group III (IUGR).

\begin{tabular}{|c|c|c|c|c|c|c|c|c|}
\hline \multirow[b]{2}{*}{ Parameter } & \multicolumn{2}{|c|}{$\begin{array}{l}\text { Fetus mass } \\
(600-3,270 \mathrm{~g})\end{array}$} & \multicolumn{2}{|c|}{$\begin{array}{l}\text { Fetus height } \\
(29-52 \mathrm{~cm})\end{array}$} & \multicolumn{2}{|c|}{$\begin{array}{l}\text { Mass-to-height } \\
(21-64 \mathrm{~g} / \mathrm{cm})\end{array}$} & \multicolumn{2}{|c|}{$\begin{array}{l}\text { Pregnancy duration } \\
\text { (30-41 weeks) }\end{array}$} \\
\hline & $\mathrm{k}$ & P-value & $\mathrm{k}$ & P-value & $\mathrm{k}$ & P-value & $\mathrm{k}$ & P-value \\
\hline cfDNA & -0.63 & $<0.0001$ & -0.74 & $<0.0001$ & -0.63 & $<0.0001$ & -0.6 & $<0.0001$ \\
\hline DNase I & 0.01 & 0.92 & 0.02 & 0.8 & 0.01 & 0.8 & 0.1 & 0.6 \\
\hline cfDNA/DNase I & -0.55 & 0.0004 & -0.62 & $<0.0001$ & -0.54 & 0.0005 & -0.5 & 0.001 \\
\hline
\end{tabular}

cfDNA, cell-free DNA.
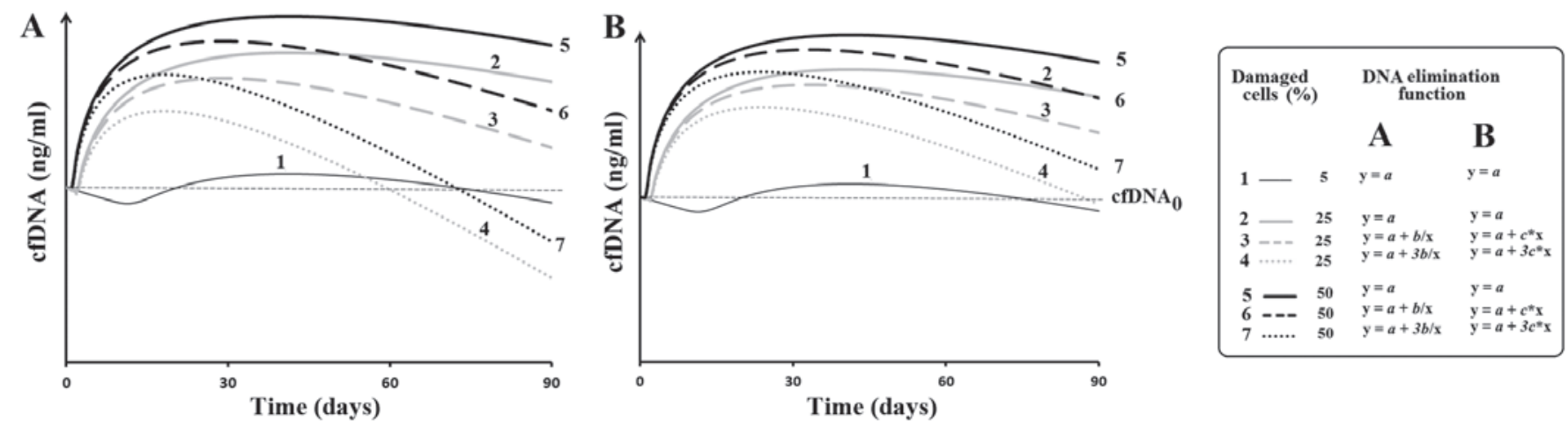

Figure 2. Modeling of changes of cfDNA concentration. Curve 1 indicates the process in a healthy body: low number of damaged cells ( $3 \%$ of total), low level of cell damage ( $5 \pm 3$ units of 100 possible) and a constant level of activity of the elimination system (function for cfDNA elimination is $\mathrm{y}=\mathrm{A} 0$ ). The amount of DNA varies slightly around the initial level (dashed line). Curve 2 indicates the level of cell damage increased 5 -fold ( $25 \pm 5$ units). DNA elimination function is not changed $(\mathrm{y}=\mathrm{A} 0)$. Increased levels of cell damage lead to increased concentration of cfDNA. Curve 3 indicates the level of cell damage increased 5 -fold ( $25 \pm 5$ units). (A) DNA elimination function is $y=A 0+b / x$ or (B) $y=A 0+c * x$. The elimination activity increases in the first $24 \mathrm{~h}$ following exposure to damaging factors. Further activity remains at the current level. Curve 4 indicates the level of cell damage increased 5 -fold ( $25 \pm 5$ units). DNA elimination function is (A) $y=A 0+3 b / x$ or $y=A 0+3 c^{*} x$. Curves 5-7 indicate the conditions corresponding to curves $2-4$, except for a higher predetermined level of cell damage (50 \pm 5 units). cfDNA, cell-free DNA.

that chronic cardiovascular diseases also lead to a decrease in total cfDNA concentration, while acute myocardial infarction accompanied by a sharp increase of the DNA in the first day of the disease (22).

In case of pathological problems with placenta that is associated with IUGR, cells of the placenta have increased cell death rate due to both apoptosis and necrosis $(28,29)$. cfDNA of the dead cells of the placenta enter maternal bloodstream, increasing cfDNA concentration. This placental cfDNA is believed to increase apoptosis in maternal cells, thus, causing the cfDNA concentration to increase even more. Thus, in cases of IUGR it is logical to expect increase of total cfDNA concentration in maternal blood plasma. Apparently, this happens during early stages of the pathological processes, before the defense mechanism of cfDNA elimination is activated (Fig. 2).

Increased DNase I activity is a sign of pathological process, that is accompanied by cell death. The authors have previously found it to be true in cases of heart attack, ischemic heart disease (22) and in patients that are chronically subjected to ionizing radiation (23). In cases of pregnancy with IUGR, the results indicated a persistent increase in DNase I activity in blood plasma that is an evidence of increased cell death rate in the patient's organism. Interestingly, subgroup IIa and IIIa exhibited abnormally abrupt decrease in cfDNA level under relatively low activity of DNase I compared to group I. In cases of these women cfDNA concentration does not depend on DNase I activity. In the patients from subgroups IIa and IIIa the decrease in cfDNA concentration as the DNase I activity increases is more abrupt than in group I.

All these facts are suggesting that DNase I is not the single component of the cfDNA eliminating system during pregnancy. Other important factors may be cfDNA-antibody binding and increased kidney function that eliminates short cfDNA fragments. In addition, expression of other cfDNA hydrolyzing enzymes in blood plasma of pregnant women can be increased. This assumption requires further experimental investigation.

High activity of cfDNA elimination system during pregnancy distorts the results and makes it difficult to analyze cfDNA concentration, especially in cases of IUGR. This may be a possible explanation why the data concerning cfDNA concentration in blood of pregnant women with pathologies are so controversial (1). However, if three factors (cfDNA concentration, DNase I activity, cfDNA/DNase I index) are taken into account, it is possible to develop a screening method that will allow monitoring cell death rate in pregnant patients. 
These data informs us about cell death rate and cfDNA elimination system activity.

\section{References}

1. Gahan PB and Stroun M: The Biology of Circulating Nucleic Acids in Plasma and Serum (CNAPS). In: Extracellular Nucleic Acids. Kikuchi Yo and Rykova EY (eds). Springer, Berlin, pp167-189, 2010.

2. Mittra I, Nair NK and Mishra PK: Nucleic acids in circulation: Are they harmful to the host? J Biosci 37: 301-312, 2012.

3. Rykova EY, Morozkin ES, Ponomaryova AA, Loseva EM, Zaporozhchenko IA, Cherdyntseva NV, Vlassov VV and Laktionov PP: Cell-free and cell-bound circulating nucleic acid complexes: Mechanisms of generation, concentration and content. Expert Opin Biol Ther 12 (Suppl 1): S141-S153, 2012.

4. van der Vaart M and Pretorius PJ: Characterization of circulating DNA in healthy human plasma. Clin Chim Acta 395: 186, 2008.

5. van der Vaart M and Pretorius PJ: Circulating DNA. Its origin and fluctuation. Ann N Y Acad Sci 1137: 18-26, 2008

6. van der Vaart $\mathrm{M}$ and Pretorius PJ: The origin of circulating free DNA. Clin Chem 53: 2215, 2007.

7. Gahan PB: Biology of circulating nucleic acids and possible roles in diagnosis and treatment in diabetes and cancer. Infect Disord Drug Targets 12: 360-370, 2012.

8. Gahan PB, Anker P and Stroun M: Metabolic DNA as the origin of spontaneously released DNA? Ann N Y Acad Sci 1137: 7-17, 2008

9. Gahan PB and Stroun M: The virtosome-a novel cytosolic informative entity and intercellular messenger. Cell Biochem Funct 28: 529-538, 2010.

10. Lo YM, Corbetta N, Chamberlain PF, Rai V, Sargent IL, Redman CW and Wainscoat JS: Presence of fetal DNA in maternal plasma and serum. Lancet 350: 485-487, 1997.

11. Gahan PB: Circulating nucleic acids in plasma and serum: Applications in diagnostic techniques for noninvasive prenatal diagnosis. Int J Womens Health 5: 177-186, 2013.

12. Bianchi DW and Wilkins-Haug L: Integration of noninvasive DNA testing for aneuploidy into prenatal care: What has happened since the rubber met the road? Clin Chem 60: 78-87, 2014.

13. Sifakis S, Koukou Z and Spandidos DA: Cell-free fetal DNA and pregnancy-related complications (Review). Mol Med Rep 11: 2367-2372, 2015.

14. Hahn S, Rusterholz C, Hösli I and Lapaire O: Cell-free nucleic acids as potential markers for preeclampsia. Placenta 32 (Suppl) S17-S20, 2011.

15. Dugoff L, Barberio A, Whittaker PG, Schwartz N, Sehdev H, Bastek JA: Cell-free DNA fetal fraction and preterm birth. Am J Obstet Gynecol 215: 231.e1-7, 2016.

16. Sekizawa A, Jimbo M, Saito H, Iwasaki M, Matsuoka R, Okai T and Farina A: Cell-free fetal DNA in the plasma of pregnant women with severe fetal growth restriction. Am J Obstet Gynecol 188: 480-484, 2003.
17. Gourvas V, Dalpa E, Konstantinidou A, Vrachnis N, Spandidos DA and Sifakis S: Angiogenic factors in placentas from pregnancies complicated by fetal growth restriction (Review). Mol Med Rep 6: 23-27, 2012.

18. Smid M, Galbiati S, Lojacono A, Valsecchi L, Platto C, Cavoretto P Calza S, Ferrari A, Ferrari M and Cremonesi L: Correlation of fetal DNA levels in maternal plasma with Doppler status in pathological pregnancies. Prenat Diagn 26: 785-790, 2006.

19. Alberry MS, Maddocks DG, Hadi MA, Metawi H, Hunt LP, Abdel-Fattah SA, Avent ND and Soothill PW: Quantification of cell free fetal DNA in maternal plasma in normal pregnancies and in pregnancies with placental dysfunction. Am J Obstet Gynecol 200: 98.e1-98.e6, 2009.

20. Al Nakib M, Desbrière R, Bonello N, Bretelle F, Boubli L, Gabert $J$ and Levy-Mozziconacci A: Total and fetal cell-free DNA analysis in maternal blood as markers of placental insufficiency in intrauterine growth restriction. Fetal Diagn Ther 26: 24-28, 2009.

21. Veĭko NN, Bulycheva NV, Roginko OA, Veǔko RV, Ershova ES, Kozdoba OA, Kuz'min VA, Vinogradov AM, Iudin AA and Speranski1 AI: Ribosomal repeat in the cell free DNA as a marker for cell death. Biomed Khim 54: 78-93, 2008 (In Russian).

22. Korzeneva IB, Kostuyk SV, Ershova LS, Osipov AN, Zhuravleva VF, Pankratova GV, Porokhovnik LN and Veiko NN: Human circulating plasma DNA significantly decreases while lymphocyte DNA damage increases under chronic occupational exposure to low-dose gamma-neutron and tritium $\beta$-radiation. Mutat Res 779: 1-15, 2015.

23. Macanovic M and Lachmann PJ: Measurement of deoxyribonuclease I (DNase) in the serum and urine of systemic lupus erythematosus (SLE)-prone NZB/NZW mice by a new radial enzyme diffusion assay. Clin Exp Immunol 108: 220-226, 1997.

24. Gannushkina IV and Konorova IL: Cell-free plasmic DNA as a blood factor determining hemodynamics in health and in vascular pathology]. Patol Fiziol Eksp Ter: 2-10, 2008 (In Russian).

25. Speranskii AI, Kostyuk SV, Veiko NN and Kalashnikova EA: Enrichment of extracellular DNA from the cultivation medium of human peripheral blood mononuclears with genomic $\mathrm{CpG}$ rich fragments results in increased cell production of IL-6 and TNF-a via activation of the NF-kB signaling pathway. Biomed Khim 62: 331-340, 2016 (In Russian).

26. Seredkina N, Zykova SN and Rekvig OP: Progression of murine lupus nephritis is linked to acquired renal Dnasel deficiency and not to up-regulated apoptosis. Am J Pathol 175: 97-106, 2009.

27. Fenton K, Fismen S, Hedberg A, Seredkina N, Fenton C, Mortensen ES and Rekvig OP: Anti-dsDNA antibodies promote initiation, and acquired loss of renal Dnasel promotes progression of lupus nephritis in autoimmune (NZBxNZW)F1 mice. PLoS One 4: e8474, 2009.

28. Kolialexi A, Tsangaris GT, Antsaklis A, Tzortzatou F, Amentas C, Koratzis A and Mavrou A: Apoptosis in maternal peripheral blood during pregnancy. Fetal Diagn Ther 16: 32-37, 2001.

29. Kolialexi A, Tsangaris GT, Mavrou A, Antsaklis A, Tzortzatou F, Touliatou V and Metaxotou C: Use of annexin V antibody to identify apoptotic cells during pregnancy. Ann N Y Acad Sci 945: 145-150, 2001. 